\title{
Variation in social organisation of lions with particular reference to the Asiatic Lions Panthera leo persica (Carnivora: Felidae) of the Gir forest, India
}

\author{
V. Meena \\ Wildlife Institute of India, P.O.Box 18, Chandrabani, Dehradun, Uttarakhand 248001, India \\ Email: meena.venktraman@gmail.com
}

Date of publication 26 March 2009

ISSN 0974-7907 (online) | 0974-7893 (print)

Editor: Mewa Singh

Manuscript details:

Ms \# 02095

Received 12 November 2008

Final received 05 March 2009

Finally accepted 12 March 2009

Citation: Meena, V. (2009). Variation in social organization of lions with particular reference to the Asiatic Lions Panthera leo persica (Carnivora: Felidae) of the Gir forest, India. Journal of Threatened Taxa 1(3): 158-165.

Copyright: @ V. Meena 2009. Creative Com mons Attribution 3.0 Unported License. JoTT allows unrestricted use of this article in any medium for non-profit purposes, reproduction and distribution by providing adequate credit to the authors and the source of publication.

Author Details: After completing post graduation in Ecology and Environmental sciences from the Pondicherry University, V. Meena has completed her PhD on the Asiatic Lions on the topic "Reproductive Strategy and Behaviour of Male Asiatic Lions" involving extensive fieldwork spanning six years. She continues her affiliation with the Wildlife Institute of India.

Acknowledgement: I would like to thank Drs. Bruce Patterson, Norman Monks, Andrew Loveridge and Paul Funston for responding to my questionnaire and clarifying data from literature. I am also grateful to the Wildlife Institute of India for providing me with facilities for preparing the manuscript.
Abstract: Sociality is one of the distinctive features of Lions (Panthera leo), which are the only social felids. Their evolutionary history is important both for understanding the evolution of sociality and that of other sympatric species owing to their widespread distribution throughout the entire Holarctic region during the Pleistocene. Lion grouping patterns, cooperative behaviour and strategies vary throughout their range and in different habitats. Their resilience in diverse habitats facing a variety of conservation pressures is largely owing to this plasticity of lion social behaviour. This review describes the variation in social organisation of lions in 11 habitats across Africa, taking into account relevant ecological parameters. The social organization of the Asiatic Lion is described from this perspective using the results of previous studies and of a five-year study conducted between 2002 and 2006 in the Gir forest of India.

Keywords: Asiatic Lion, Gir protected area, Panthera leo, social organisation

\section{INTRODUCTION}

Carnivores are mostly solitary (Ewer 1973). However, certain taxonomic groups among carnivores, such as canids and herpestids, have a tendency for social living (Gittleman 1989). Since social living does not show a serial evolutionary trend across taxa, it appears that group living has evolved in each major taxonomic family independently across the order (Gittleman 1989). Diverse selective pressures, such as optimum resource exploitation, competition and reproduction have contributed to the evolution of sociality among carnivores, the basis of which has been reviewed by several authors (Eaton 1979; Macdonald 1983; Gittleman 1989). Hunting and killing of large prey, anti-predator defence, social learning and information transfer, alloparental care, and survival in hostile environments are potential advantages that promote social living (Macdonald 1983; Gittleman 1989). The resource dispersion hypothesis explains the evolution of sociality, and states that dispersion and abundance of resources causes variation in the social system of carnivores (MacDonald 1983). These variations are moulded both by ecological constraints and benefits (MacDonald 1983). Typically, there are several types of carnivore grouping that represent functional responses to both the environment as well as kinship and relatedness, namely foraging groups (related to hunting success), feeding groups (related to sharing of food), population groups (related to sharing a common home-range) and breeding groups (related to mating) (Gittleman 1989). Behaviours such as guarding of foraging and breeding grounds, mutual regurgitation, sharing of reproductive opportunities among group members and communal suckling or rearing of young ones have been associated with kin selection (Bertram 1979).

Felids exhibit intraspecific variation in sociality: Leopards (Panthera pardus) are solitary (Bailey 1993), Tigers (Panthera tigris) are capable of social living (Sunquist 1991) and male Cheetahs (Acinonyx jubatus) exhibit facultative sociality to improve their reproductive success (Caro 1994), while Lions (Panthera leo) are the only truly social carnivores among felids (Bertram 1975). Group living thus distinguishes lions from rest of the Panthera group (Yamaguchi et al. 2004).

Discussions of sociality in carnivores usually involve comparisons with lions (Sunquist 1981; Caro 1994; Stander et al. 1997), which live together in social units called prides that are described as fission-fusion interactions (Schaller 1972). Group territoriality, group hunting and communal cub rearing form the basis of social cooperation (Grinnell et al. 1995; Heinsohn \& Packer 1995) that are distinguished as optimum foraging groups that maximise hunting success (Clark 1987; Giraldeau \& Gillis 1988), associations that counteract competition with other species (Coraco \& Wolf 1975; Cooper 1991) and associations that maximise reproductive success (Packer \& Pusey 1982). The lion social 
structure defines the way in which available resources are used or shared. This aspect of lion sociality has been well documented in the Serengeti Lions of Africa (Schaller 1972; Bertram 1975; Packer \& Pusey 1982; Packer \& Pusey 1983; Packer \& Pusey 1987; Packer et al. 1988; Grinnell et al. 1995). However, the fact that lions do not form standard patterns of social living is often overlooked. Lion social systems are dynamic and vary with respect to habitat, anthropogenic pressures, dependency on livestock, prey availability and competition (Schaller 1972; Cooper 1991; Hanby et al. 1995; Hemson 2003; Funston et al. 2007). While popular conceptions of lion social behaviour are based on the predominant literature on lion behaviour in the open plains of the Serengeti, several recent studies have focused on providing a broader perspective on African Lion populations. Some studies have reviewed the population, density and status of lions across Africa (Chardonnet 2002; Bauer \& van der Merwe 2004), while others have reviewed the social organisation of lions (Hemson 2003; Purchase 2004; Funston 2007 ) based on chosen habitat variables, albeit in varied contexts. A detailed review, taking into account prey and diet parameters (including livestock uptake), habitat and climate, social structure, density, home-range has not been undertaken. It may be possible to ascertain or speculate on the drivers of patterns of lion social organisation in different habitats if such a database is made available. This review presents baseline data on lion social organisation and habitat-specific ecological parameters (Table 2-4), including pride and coalition composition, male-female interaction, pride size, home-range, habitat, prey availability and competition. The data has been sourced from the literature and personal communications with experts in the field.

\section{Genetic variation of lion populations}

The evolution of modern ungulates, the radiation of Felinae as well as the extinction of the earliest known ancestor of modern cats, the sabre-tooth cats, occurred during the Pleistocene (Turner \& Anton 1997). Members of Panthera share a common lineage up to the Pliocene, and later lions developed distinctive features, such as group living and manes (Yamaguchi et al. 2004). Lions have attained a wide distribution range during their evolutionary history and have influenced the evolution of many sympatric species (Eisenberg 1981). Thus, an understanding of their evolutionary history is of great importance to understand the evolution of other prey and carnivore species, as well as the evolution of cooperative behaviour.

Two models have been proposed to explain the diversification of lions: multiregional origin and single origin replacement (Barnett et al. 2006). The former proposes longterm evolution and diversification of present-day lions, while the latter proposes that a single population of lions replaced the older populations in Africa and southwestern Eurasia following a population bottleneck (Yamaguchi et al. 2004; Barnett et al. 2006). Two distinct lineages, namely the Holarctic Cave Lion (Panthera leo spelaea) and the Modern Lion (Panthera leo spp.) existed at the end of Pleistocene (Burger et al. 2005). Traditionally, 12 and later eight subspecies of Panthera leo had been classified based on location, mane appearance, size and distribution (Burger et al. 2005; Barnett et al. 2006) (Table 1). Lions are classified into three geographic populations on the basis of their recent evolutionary history, namely, northern
African-Asian, southern African and middle African populations (Barnett et al. 2006).

Recent studies on the phylogeographic history of modern lions based on analysis of mitochondrial DNA sequences have concluded that the limited variations do not merit taxonomic distinction among extant African Lions (Dubach et al. 2005), thereby indicating a single African origin model of modern lion evolution (Barnett et al. 2006). Based on the above studies, all sub-Saharan lions are classified into a single subspecies $\left(\mathrm{O}^{\prime}\right.$ Brien et al. 1987; Dubach et al. 2005). However, they may be divided into two main clades to the west and east of the Great Rift Valley, based on the fact that lions from Tsavo in eastern Kenya are genetically closer to lions in the Transvaal (South Africa) than to those in the Aberdare Range in western Kenya (Barnett et al. 2006).

Two distinct subspecies of extant lions, namely, Panthera leo leo and Panthera leo persica have been recognized to have diverged in recent times, about 55,000 and 200,000 years ago (O' Brien et al. 1987). Free-ranging lions today exist as two disjunct populations: P. l. leo in Africa and P. l. persica in India. The former are presently found in savannah habitats across subSaharan Africa, while the only living representatives of the latter occur in the Gir forest of India (Nowell \& Jackson 1996).

\section{Asiatic lions: Distribution and status}

Historically, the Asiatic Lion had a wide distribution extending from Syria across the Middle East to eastern India (Kinnear 1920; Joslin 1973). Within the Saurashtra region they were found in Dhrangadhra, parts of Jasdan, Chotila, Alech hills, Barda hills, Girnar and Gir (Dalvi 1969). By the turn of the $19^{\text {th }}$ century the lion population was fragmented, and ultimately became limited to the Gir forest (Dalvi 1969). In recent years an increase in lion populations has resulted in an increase in density within Gir, and consequently lions have dispersed and established themselves outside the protected area (Singh 1997). The present population estimate is 359 lions, including 291 within the protected area and "satellite populations" of 68 (Gujarat Forest Department census report 2005).

\section{African Lions: Distribution and status}

The African Lion population has been estimated to be between 16,500 and 30,000 (Bauer \& van der Merwe 2004). They exist both as fragmented populations in west and central Africa, and as a continuous large population in east and southern Africa (Bauer \& van der Merwe 2004) (Fig. 1).

\section{Lion Social Organisation: Classic pattern from studies in the Serengeti}

A pride consists of 2-18 females and a coalition of males that have entered the pride from elsewhere and associate with it during their tenure (Schaller 1972; Bertram 1975; Bygott et al. 1979; Packer \& Pusey 1982). Interestingly, there appears to be no functional dominance hierarchy within prides (Schaller 1972; Bertram 1975; Bygott et al. 1979; Packer \& Pusey 1982). Female companions of a pride are always closely related, male companions are either closely related or unrelated, and mating partners are usually unrelated (Packer et al. 1991).

At the age of three, subadult females are either recruited into the pride or driven out of it depending upon the existing adult population (Bertram 1975). At three years of age male 
Table 1. Subspecies classification of lions (Burger et al. 2004).

\begin{tabular}{ll}
\hline spelaea Group & \\
P. I. fossilis & Early Middle Pleistocene European Cave Lion \\
P. I. vereshchagini & East Siberian or Beringian Cave Lion \\
P. I. atrox & North American Cave Lion \\
P. I. spelaea & Upper Pleistocene European Cave Lion \\
leo Group & \\
P. I. persica & Asiatic, Persian or Indian Lion \\
P. I. leo & (Barbary Lion) All extant African Lions \\
senegalensis Group & \\
P. I. senegalensis & West African Lion \\
P. I. azandica & North East Congo Lion \\
P. I. nubica & East African or Masai Lion \\
P. I. bleyenberghi & Southwest African or Katanga Lion \\
P. I. krugeri & Southeast African or Transvaal Lion \\
P. I. melanochaita & Cape Lion \\
\hline
\end{tabular}

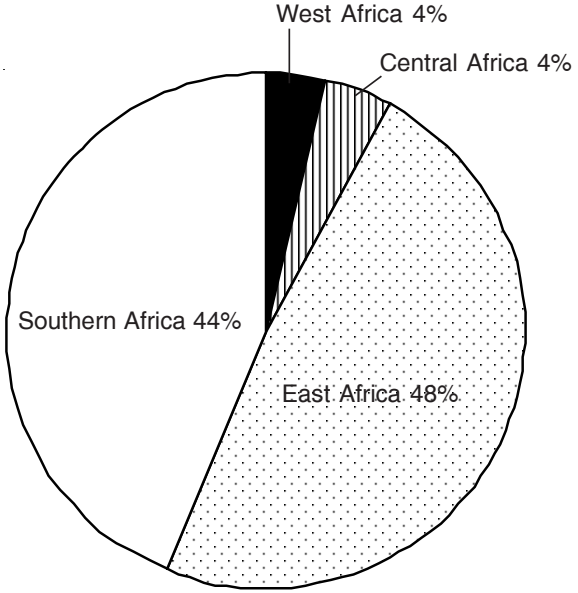

Figure 1. Distribution of lions in Africa (Bauer \& van der Merwe 2004)

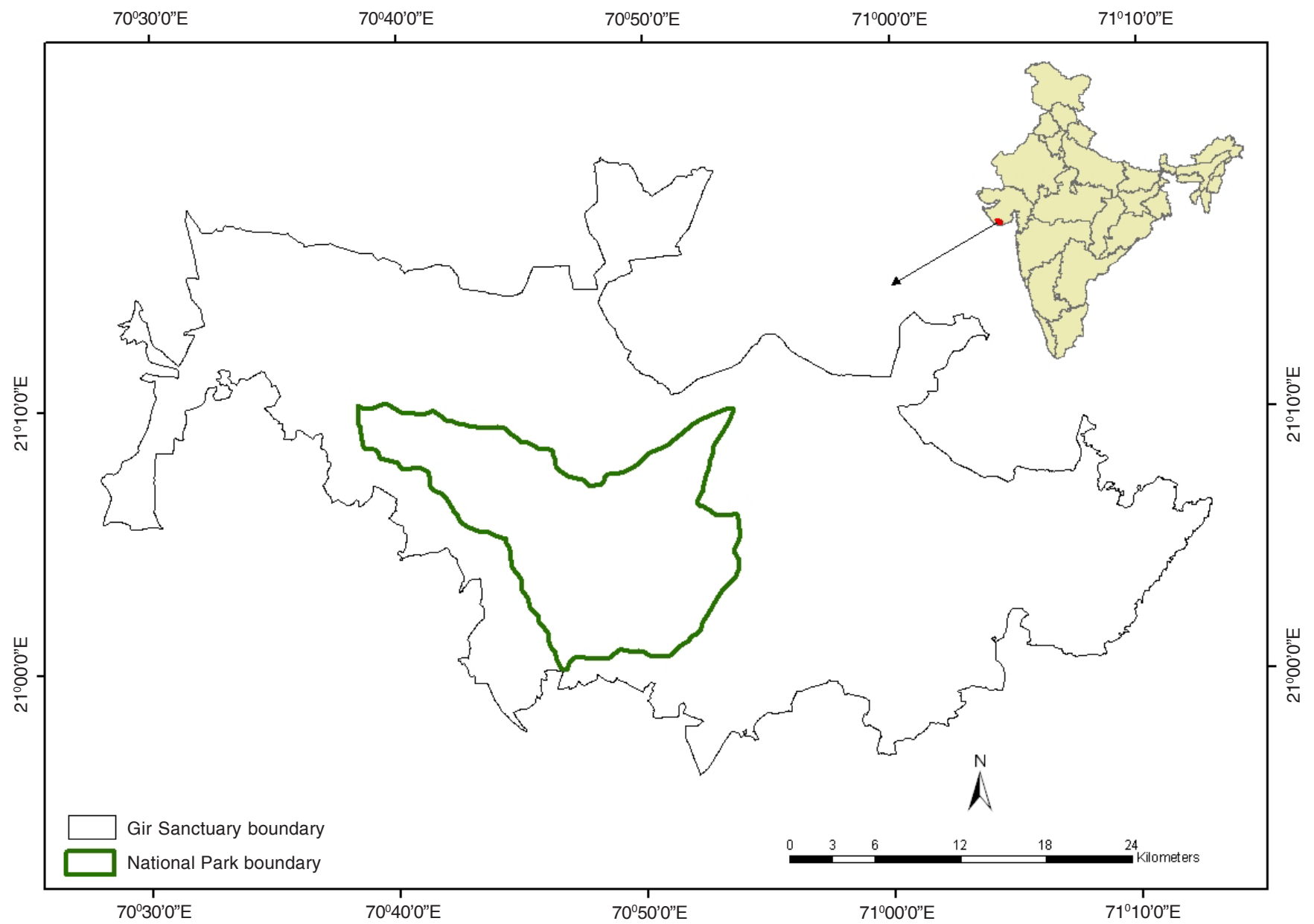

Figure 2. Location of the Gir Sanctuary and National Park in western India

lions are either expelled or leave their natal prides voluntarily (Bertram 1975). During the nomadic phase of their lives they form coalitions of 2-9 individuals with either brothers and cousins from the same pride or with non-related males (Packer \& Pusey 1997). A successful coalition gains temporary but exclusive access to a group of females until ousted by another coalition (Bygott et al. 1979). Successful male coalitions become resident in their first pride when they are about four years old
(Packer \& Pusey 1987), and typically remain in a pride for 2-3 years, fathering only one cohort per pride (Packer et al. 1988). Nomadic lions are not necessarily of a different population, but are surplus from the resident breeding populations (Schaller 1972; Bertram 1975). Most nomads are males looking to establish and wrest control of prides from other coalitions (Schaller 1972) and include both sub-adult males and old males expelled from their territories by other males (Schaller 1972). 
Table 2. Description of location and habitat of lion habitats

\begin{tabular}{|c|c|c|c|c|c|c|}
\hline Study area & Region & Country & $\begin{array}{l}\text { Park area } \\
\left(\mathbf{k m}^{2}\right)\end{array}$ & Vegetation & Cover & Author \& Source \\
\hline Kruger NP & Southern Africa & S. Africa & 23,700 & Open woodland savanna & Mixed & P.J. Funston pers. comm. \\
\hline Greater Tsavo Ecosystem & East Africa & Kenya & 20,000 & Acacia - Commiphora woodland & Medium & B. Patterson pers. comm. \\
\hline Selous Game Reserve & East Africa & Tanzania & 92,000 & $\begin{array}{l}\text { Wooded savanna, Miomom Combretum } \\
\text { thickets }\end{array}$ & Medium & Spong 2002 \\
\hline Etosha NP & Southern Africa & Namibia & 22,270 & Short grass plains & Open & Stander 1992 \\
\hline Serengeti & East Africa & Tanzania & 40,000 & Acacia woodlands /plains & Open & Hanby et al. 1995 \\
\hline Luangwa Valley & Southern Africa & Zambia & 355 & Mixed & Medium & Yamazaki 1996 \\
\hline Mid - Zambezi & Southern Africa & Zimbabwe & 2,196 & Alluvial/ Colophospermum/ dry & Closed & N. Monks pers. comm. \\
\hline Masai Mara NP & East Africa & Kenya & 1,530 & Open wooded grassland & & Ogutu \& Dublin 2002 \\
\hline Ngorongoro Crater & East Africa & Tanzania & 250 & Savanna & Open & Hanby et al. 1995 \\
\hline Chobe NP & & & 11,700 & Savanna & Mixed & Cooper 1991 \\
\hline Hwange NP & Southern Africa & Zimbabwe & 14,600 & $\begin{array}{l}\text { North-west area: Coleospermum } \\
\text { mopane woodland and scrub. Kalahari } \\
\text { sand: Baikiaea plurijuga woodland }\end{array}$ & Mixed & Loveridge 2005 \\
\hline Gir Sanctuary and NP & Gujarat State & India & 1,883 & Dry teak forest & Mixed & Pathak et al. 2008 \\
\hline
\end{tabular}

Table 3. Details on prey related parameters and competition for the lion habitats

\begin{tabular}{|c|c|c|c|c|c|c|c|}
\hline Study Area & $\begin{array}{l}\text { Prey } \\
\text { Diversity }\end{array}$ & $\begin{array}{l}\text { Prey } \\
\text { Availability }\end{array}$ & $\begin{array}{l}\text { Prey biomass } \\
\left(\mathbf{k g} / \mathbf{k m}^{2}\right)\end{array}$ & $\begin{array}{l}\text { Livestock } \\
\text { availability }\end{array}$ & $\begin{array}{l}\text { Livestock } \\
\text { intake }\end{array}$ & $\begin{array}{l}\text { Competing } \\
\text { predators }\end{array}$ & Reference \\
\hline Kruger NP & 5 & High & 246 & None & Low & Low & East 1984 \\
\hline Greater Tsavo Ecosystem & & Seasonal & Data deficient & High & Low & Medium & East 1984 \\
\hline Selous Game Reserve & 14 & High & 1,874 & None & No & Low & Caro et al. 1998 in Hemson 2003 \\
\hline Etosha NP & 11 & Seasonal & 283 & & & Low & Coe et al. 1976; East 1984 \\
\hline Serengeti & 13 & Seasonal & 970 & None & None & Low & Hanby et al. 1995 \\
\hline Luangwa Valley & $\begin{array}{l}\text { Data } \\
\text { deficient }\end{array}$ & Data deficient & 10,003 & Data deficient & Data deficient & & $\begin{array}{l}\text { Ndhlovu \& Balakrishnan } 1991 \text { in } \\
\text { Hemson } 2003\end{array}$ \\
\hline Mid - Zambezi & high & High & Data deficient & None & None & Medium & N. Monks pers. comm. \\
\hline Masai Mara NP & 8 & High & 10,335 & Medium & Medium & Medium & Ogutu \& Dublin 2002 \\
\hline Ngorongoro Crater & 8 & High & 15,660 & None & None & & Hanby et al. 1995 \\
\hline Chobe NP & low & High & 11,693 & Data deficient & Data deficient & Low & Cooper 1991 \\
\hline Hwange NP & & & 30 & No & No & High & East 1984 \\
\hline Gir Sanctuary and NP & 7 & High & 2,764 & High & High & Low & Khan et al. 1995 \\
\hline
\end{tabular}

Nomadic females are those expelled from their natal territories (Schaller 1972).

\section{Lion grouping strategies \\ I. Reproductive success:}

Reproductive success of individuals of each sex depends on the number of like-sex companions (Packer \& Pusey 1987).

Female strategies: Females cooperate to defend their hunting grounds, denning sites and water holes from other prides and at the same time also communally suckle and raise their cubs and jointly protect them from infanticidal males (Packer \& Pusey 1997).

Male strategies: Larger coalitions are more likely to gain residence in a pride, remain in residence longer and gain access to more females than small coalitions (Bygott et al. 1979). Group formation thus results in greater reproductive success (Bygott et al. 1979; Packer et al. 1988). Infanticide in lions is another male reproductive strategy whereby males terminate a female's investment in the offspring of other males, which in turn stimulates female sexual receptivity (Hardy 1974; Bertram 1975). Incoming males that take over a pride kill small cubs and oust subadult females below breeding age along with resident subadult males (Pusey \& Packer 1983).

Subadult strategies: Although reproductive success increases with group size, individual reproductive success generally becomes lower (Packer et al. 1988). Resident male coalitions are able to successfully raise one cohort during their tenure period (Bygott et al. 1979). In a situation where birth is synchronous following a takeover, closely-related males are able to strategically disperse together and have the advantage of entering new prides intact (Packer \& Pusey 1987). Therefore kinship is essential for the maintenance of larger coalitions, a strategy that would compensate for low individual reproductive success (Packer et al. 1991).

\section{Hunting success:}

Hunting success is another important factor determining the social structure of lions. Availability of resources such as denning sites, water and a stable, high density resident preybase supports a high density and stable lion population, with smaller home-range with much less spatial overlap between prides (Scheel \& Packer 1995; Ogutu \& Dublin 2002; Spong 2002). For instance lion density was 3.3 times higher per $\mathrm{km}^{2}$ in Ngorongoro Crater compared to the Serengeti plains, where the availability of prey varied (Scheel \& Packer 1995). Hunting success has been shown to increase with increase in group size, especially in hunting down large prey (Stander 1992; Funston et al. 2001). In open areas the hunting success of males is reduced owing to the fact that they are much slower and more conspicuous; therefore by associating with pride females throughout their tenure they can appropriate prey kills (Bertram 1979). In closed areas, however, males can obtain more meat by hunting alone than by scavenging from females (Funston et al. 1998). 
Table 4. Details on lion social organization for the lion habitats

\begin{tabular}{|c|c|c|c|c|c|c|c|c|}
\hline Study Area & $\begin{array}{l}\text { Population } \\
\text { estimate }\end{array}$ & $\begin{array}{l}\text { Home } \\
\text { range }\left(\mathbf{k m}^{2}\right)\end{array}$ & $\begin{array}{l}\text { Density } \\
/ 100 \text { km² }^{2}\end{array}$ & $\begin{array}{l}\text { Average } \\
\text { group size }\end{array}$ & $\begin{array}{l}\text { Male group } \\
\text { size }\end{array}$ & $\begin{array}{l}\text { Female } \\
\text { group size }\end{array}$ & $\begin{array}{l}\text { M-F interaction } \\
\text { (during tenure) }\end{array}$ & Source \\
\hline Kruger NP & 2,200 & 150 & 10.5 & 11.8 & 2.1 & 4.5 & Throughout & $\begin{array}{l}\text { P.J. Funston } \\
\text { pers. comm. }\end{array}$ \\
\hline Greater Tsavo Ecosystem & 675 & & Low & 8 & 1 & 7.4 & Throughout & $\begin{array}{l}\text { B. Patterson } \\
\text { pers. comm. }\end{array}$ \\
\hline Selous Game Reserve & 3,750 & 52.4 & 16 & 5.3 & 2.4 & 3.4 & Throughout & Spong 2002 \\
\hline Etosha NP & 230 & 600 & 2 & 4.2 & 1.5 & 4.8 & Throughout & $\begin{array}{l}\text { Stander 1992; } \\
\text { Oxford et al. } 1998\end{array}$ \\
\hline Serengeti & 2,500 & 200 & 10 & 11.5 & 3.1 & 5.4 & Throughout & Hanby et al. 1995 \\
\hline Luangwa valley & 49 & 58 & 12.7 & 9.7 & 2 & 3.8 & Occasional & Yamazaki 1996 \\
\hline Mid - zambezi & $120^{*}$ & & 5.2 & 7.7 & 2 & 8 & Throughout & $\begin{array}{l}\text { N. Monks } \\
\text { pers. comm. }\end{array}$ \\
\hline Masai mara NP & 547 & 71 & 30 & 22 & 2.4 & 9.2 & Throughout & $\begin{array}{l}\text { Ogutu \&Dublin } \\
2002\end{array}$ \\
\hline Ngorongoro Crater & 53 & 45 & 40 & 16.25 & 3.25 & 3.5 & Throughout & Hanby et al. 1995 \\
\hline Chobe NP & 213 & 1000 & 5 & 7 & 2 & 7 & Occasional & Cooper 1991 \\
\hline Hwange NP & 250 & $\begin{array}{l}\text { Male: } 700 \\
\text { Female: } 345\end{array}$ & 3.6 & & 1.9 & 2.77 & Occasional & Loveridge 2005 \\
\hline Gir Sanctuary and NP & 360 & $\begin{array}{l}\text { Male: } 85 \\
\text { Female: } 35\end{array}$ & 11 & & 1.4 & 1.3 & Occasional & Meena 2008 \\
\hline
\end{tabular}

* only for Mana pools National Park

\section{Tackling competition:}

Pride size and lion associations in some areas are determined by the presence of competing species, the Spotted Hyenas (Cooper 1991). Several nomadic lions form aggregates of up to 17 and associate with prides to form stable associations in order to defend against Spotted Hyenas (Cooper 1991).

\section{Prudent strategies for males:}

The association of adult male coalitions and female prides may be occasional or throughout the tenure of territorial males and may vary in different areas. In open areas, males associate with the prides throughout their tenure and thus show direct parental investment by providing protection to dependent cubs from infanticidal nomadic males (Kleiman \& Malcolm 1981). In closed areas on the other hand, where intruders are less visible, males operate alone and maintain territory by patrolling, scent marking and roaring - a strategy that is effective both in discouraging rivals from entering the pride range and also in ensuring access to more prides (Funston et al 1998). Pride females in big groups on the other hand, are also able to protect their offspring without the help of pride males (Funston et al. 1998).

\section{Lion social organisation: Observation from the Gir PA}

\section{a) Park area, vegetation and cover:}

The Gir Wildlife Sanctuary and National Park (Gir PA) is located in the southern part of the Kathiawar peninsula, in the state of Gujarat in western India, extending across districts of Amreli and Junagadh between $21^{\circ} 20^{\prime}-20^{\circ} 57^{\prime} \mathrm{N} \& 70^{\circ} 27^{\prime}-$ $71^{\circ} 13^{\prime} \mathrm{E}$ (Figure 2). The Gir PA covers $1412 \mathrm{~km}^{2}$ area and is part of the greater Gir Conservation Unit about $1800 \mathrm{~km}^{2}$ in extent. The Gir consist of a series of low hills of volcanic origin with an altitudinal range of $83-524 \mathrm{~m}$, while the protected area is surrounded by flat, arid and extensively irrigated agricultural land (Singh \& Kamboj 1996). The Gir PA is divided into three management units, namely Sanctuary West (SW), National Park (NP) and Sanctuary East (SE) that vary with respect to rainfall, topography, vegetation and anthropogenic pressures (Khan et al. 1996; Singh and Kamboj 1996).
The Gir has a semi-arid climate with minimum and maximum temperature ranging from $5^{\circ}$ to $47^{\circ} \mathrm{C}$ with an average rainfall of $900 \mathrm{~mm}$. Three distinct seasons, namely, summer (March to mid-June), monsoon (mid-June to mid-October) and winter (late October to February) are identified.

The vegetation is tropical dry deciduous forest interspersed with tropical thorn forest (Champion \& Seth 1968). The forests of the Gir fall under very dry teak forests (5A/C1a, Champion \& Seth 1968). Non-teak forests, namely very dry teak forests and dry savannah forests (types 5/DS1 and 5/DS2) occur in parts of the Gir, and riverine forests occur along the principal rivers and streams (Champion \& Seth 1968). Nearly $70 \%$ of the total area of Gir (west and central) is covered with teak Tectona grandis and its associates while much of eastern part of Gir is dominated by Anogeissus latifolia. Coastal border forest, consisting of plantations of Prosopis juliflora and Casuarina equisetifolia occur along the coastal belts of Una and Kodinar talukas (Singh \& Kamboj 1996).

Tree densities (density $\pm 95 \% \mathrm{CI}$ ) vary across the park based on terrain and water availability (Khan et al. 1996). On a relative scale, the NP is most dense $\left(301 \pm 53 \mathrm{ha}^{-1}\right), \mathrm{SW}$ moderately dense $\left(268 \pm 31 \mathrm{ha}^{-1}\right)$ while SE with an open wooded grassland vegetation has the least density $\left(109 \pm 31 \mathrm{ha}^{-1}\right)($ Khan et al. 1996)

b) Prey biomass, diversity:

The wild prey base available for the larger carnivores is comprised of Chital (Axis axis), Sambar (Rusa unicolor), Nilgai (Boselaphus tragocamelus), Chousingha (Tetracerus quadricornis), Chinkara (Gazella gazella), Wild Boar (Sus scrofa), Porcupine (Hystrix indica), Common Langur (Semnopithecus achates), Rufoustailed Hare (Lepus nigricollis ruficaudata) and Peafowl (Pavo cristatus) (Singh \& Kamboj 1996). The prey is residential throughout the year and seasonal variation is minimal (Khan 1996).

An earlier estimate of total prey biomass (wild and domestic) varied in different park areas with $6,380 \mathrm{~kg} \mathrm{~km}^{-2}$ for SanctuaryWest, $3,292 \mathrm{~kg} \mathrm{~km}^{-2}$ for National Park and $10,717 \mathrm{~kg} \mathrm{~km}^{-2}$ for Sanctuary-East (Khan 1996). Wild Ungulate densities ranged from $50.8 \mathrm{~km}^{-2}$ to $0.42 \mathrm{~km}^{-2}$, Chital being the most abundant 


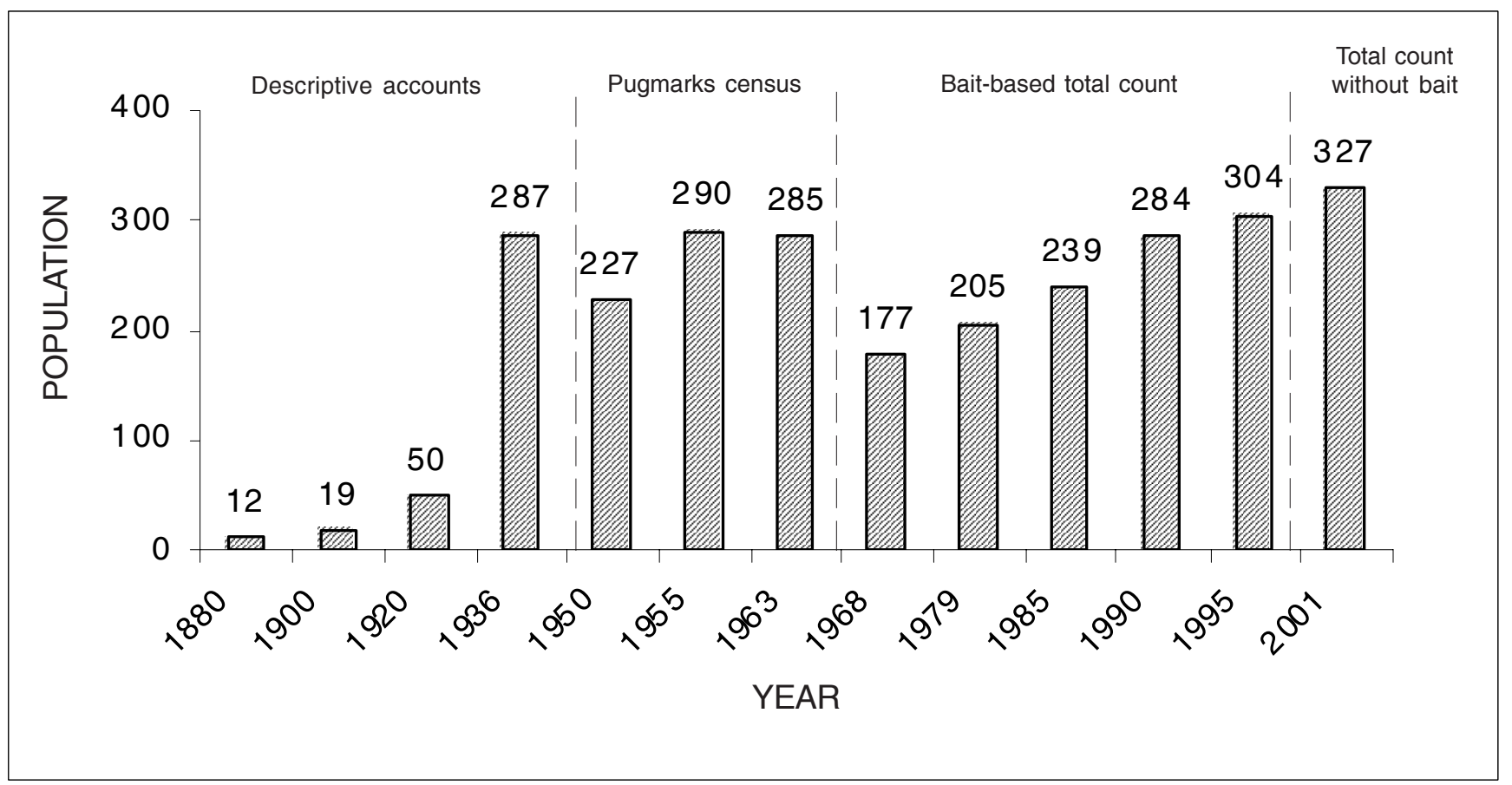

Figure 3. Population fluctuation of Asiatic Lion from the year 1880 to 2001

species (Khan 1996). The recent estimate of the overall density $( \pm \mathrm{SE})$ of all wild Ungulate species of Gir has been estimated at 48.3 ( \pm 6.1 ) individual $/ \mathrm{km}^{2}$ (Dave unpublished). Chital is the most common species with a density of $44.8( \pm 7.2)$ individual $/ \mathrm{km}^{2}$ (Dave unpublished). This apparent variation in ungulate biomass across the Gir PA may appear to be the factors responsible for the lion social structure but the above studies have not taken into account the biomass of another important prey-base available to lions, viz., that of the domestic livestock. The livestock densities are highest in SanctuaryEast and probably influencing lions to form larger groups particularly in the vicinity of the cluster of nesses in this area. On the other hand, the principal wild prey, the Chital approximately weighs $45 \mathrm{~kg}$ and cannot support the feeding requirements of large groups. Hence, the role of prey biomass in influencing lion grouping patterns requires a more detailed understanding of prey availability in different parts of the park.

\section{c) Livestock availability and intake:}

Approximately 1,06,916 livestock are present in the peripheral villages and nesses (settlements of local pastoral community within the PA) in and around Gir PA (Pathak et al. 2002). Lions are still largely dependent on livestock as part of their diet, especially in the peripheral areas outside the PA boundaries (Meena 2008).

\section{d) Competing predators:}

There is no evidence of direct competition between the three carnivores of Gir, namely Lion, Leopard (Panthera pardus) and Hyena (Hyena hyena), although a specific study on the topic is yet to be undertaken. Hyenas exist in very low densities and probably do not influence the social behaviour of lions in any way. However, lions have been observed to take over kills from leopards (Meena pers. obs.). The elusive behaviour of the latter species helps to avoid direct competition with the dominant lions.

\section{e) Population characteristics:}

The Asiatic Lion population has fluctuated widely in the past and in recent years has shown a steady increase (Fig. 3). According to the Gujarat Forest Department census, a total of 360 lions occur in Gir at an average density of 10 lions/100 $\mathrm{km}^{2}$ (Meena et al. 2007). Males and females associate only during mating and do not rest or feed together. Male groups range from 1 to 3 while female prides range from 1 to 4 and mean group sizes $( \pm \mathrm{SD})$ are $1.4 \pm 0.50(\mathrm{n}=283)$ and $1.3 \pm 0.53$ $(\mathrm{n}=291)$, respectively (Meena et al. 2007). Mean male ranges and core areas were larger $85 \mathrm{~km}^{2}( \pm 54 \mathrm{SD})$ and $10 \mathrm{~km}^{2}( \pm 3.9$ $\mathrm{SD})$ respectively than females being $35 \mathrm{~km}^{2}( \pm 7 \mathrm{SD})$ and $5 \mathrm{~km}^{2}$ $( \pm 1.7 \mathrm{SD})$. Males tend to disperse at different social phases and therefore use a much larger range (Meena 2008).

The habitat of Gir, as described earlier, is relatively denser than the open plains of the Serengeti thereby providing equal opportunities for hunting success for males and females as described in other comparable African Lion habitats such as Kruger National Park (Funston et al. 2001). The diet constituting both small and medium wild prey as well as a vulnerable livestock prey-base, are responsible for low lion group sizes and the loose bonding between male and female groups - a strategy that also increases the reproductive success of male lions. The increasing lion population and density promote smaller group sizes and greater range overlaps among Gir lions given that in the past, larger prides have been reported (Joslin 1973; Chellam 1993). However, the role of genetically closely related individuals, if at all, in driving resource-use is yet unexplored.

Thus, stable prey availability, hunting success, closed canopy (compared to open plains that lions largely inhabit), minimal competition between top predators are responsible for the 
described patterns of social organization of the Asiatic Lions.

\section{References}

Bailey, T.N. (1993). The African Leopard: Ecology and Behavior of a Solitary Felid. Columbia University Press, New York, 429pp.

Barnett, R., N. Yamaguchi, I. Barnes \& A. Cooper (2006). The origin, current diversity and future conservation of the modern lion Panther leo. Proceedings of the Royal Society of Biological Sciences 273(1598): $2119-2125$

Bauer, H. and S. van der Merwe (2004). Inventory of free-ranging lions Panthera leo in Africa. Oryx 38: 26-31

Bertram, B.C.R. (1975). The social system of lions. Scientific American. 232: 54-65.

Bertram, B.C.R. (1979). Serengeti predators and their social systems, pp.221-48. In: Sinclair, A.R.E. \& M. Norton-Griffiths (eds.). Serengeti Dynamics of an Ecosystem. Chicago, University of Chicago press, $662 \mathrm{pp}$.

Burger, J., W. Rosendahl, O. Loreille, H. Hemmer, T. Eriksson, A. Götherström, J. Hiller, M.J. Collins, T. Wess \& K.W. Alt (2004). Molecular phylogeny of the extinct Cave Lion Panthera leo spelaea. Molecular Phylogenetics and Evolution 30: 841-849.

Bygott, J.D., B.C.R. Bertram \& J.P. Hanby (1979). Male lions in large coalitions gain reproductive advantages. Nature 282(5741): 839-841

Caro, T.M. (1994). Cheetahs of the Serengeti Plains: Group Living in an asocial species. University Of Chicago Press, Chicago, $478 \mathrm{pp}$

Caro, T.M. \& D.A. Collins (1986). Male cheetahs of the Serengeti. National Geographic Research 2: 75-86.

Champion, H.G. \& S.K. Seth (1968). A Revised Survey of the Forest Types of India. Govt. of India Press: New Delhi, India.

Chardonnet, P. (2002). Conservation of the African lion: contribution to a status survey, International Foundation for the Conservation of Wildlife, France \& Conservation Force, USA.

Chellam, R. (1993). Ecology of the Asiatic Lion. Ph.D. Thesis, Saurashtra University, Rajkot, 170pp.

Clark, C.W. (1987). The lazy adaptable lions: A markovian model for group foraging. Animal Behaviour 35: 361-368.

Coe, M.J., D.H. Cumming \& J. Phillipson (1976). Biomass and production of large African herbivores in relation to rainfall and primary production. Oecologia 22: 341-354.

Cooper, S.M. (1991). Optimal hunting group size: the need for lions to defend their kills against loss to spotted hyaenas. Africa Journal of Ecology 29: 130-136

Coraco, T. \& L.L. Wolf (1975). Ecological determinants of group size of foraging lions, American Naturalist. 109: 343-352.

Dalvi, M.K. (1969). Gir lion census 1968. Indian Forester 95: 741-752.

Dubach J., B.D. Patterson, M.B. Briggs, K.Venzke, J. Flamand, P. Stander, L.Scheepers \& R.W. Kays (2005). Molecular genetic variation across the southern and eastern geographic ranges of the African lion Panthera leo. Conservation Genetics 6:15-24.

East, R. (1984). Rainfall, soil nutrient status and biomass of large African savanna mammals. African journal of Ecology. 22: 245-270

Eaton, R.L. (1979). Interference competition among carnivores: a model for the evolution of social behavior. Carnivore 2: 9-16

Eisenberg, J.F. (1981). The Mammalian Radiations. The Anthlone Press, England, 610pp.

Ewer, R.F. (1973). The Carnivores. Cornell University Press, Ithaca, New York, 344pp.

Funston, P.J., M.G.L. Mills, H.C. Biggs \& P.R.K. Richardson (1998). Hunting by male lions: ecological influences and socioecological implications. Animal Behaviour 56: 1333-1345

Funston, P.J., M.G.L. Mills \& H.C. Biggs (2001). Factors affecting the hunting success of male and female lions in the Kruger National Park. Journal of Zoology, London 253: 419-431.

Funston, P., G. Hemson, A.A. Mosser, H. Bauer, C. Packer, A. Loveridge \& L. Frank (2007) Flexible sociality ensures the persistence of lion populations when persecuted by humans. Abstract: Felid Biology and Conservation Conference, September (18-20) 2007, Oxford, 59pp.

Giraldaeu, L.A. \& D. Gillis (1988). Do lions hunt in group sizes that maximize hunters daily food returns? Animal Behaviour 36(2): 611613

Gittleman, J.L. (1989). Carnivore group living: comparative trends, pp.183-207. In: Gittleman, J.L. (ed.). Carnivore behaviour, Ecology and Evolution. Ithaca, Cornell University Press

Grinnell, J., C. Packer \& A.E. Pusey (1995). Cooperation in male lions: kinship, reciprocity or mutualism? Anim.Behav. 49: 95-105.

Hanby J.P., J.D. Bygott \& C. Packer (1995). Ecology, Demography and Behaviour of Lions in Two Contrasting habitats: Ngorongoro Crater and the Serengeti plains and their social systems, pp.315-331. In: Sinclair, A.R.E. \& P. Arcese (eds.). Serengeti II: Dynamics, Management and Conservation of an Ecosystem. Chicago: University of Chicago press, 662pp.

Heinsohn, R. \& C. Packer (1995). Complex cooperative strategies in group-territorial African lions. Science 269: 1260-1262.

Hemson, G. (2003). The Ecology and Conservation of lions: Humanwildlife conflict in semi-arid Botswana. PhD Thesis, University of Oxford.

Hrdy, S.B. (1974). Male-male competition and infanticide among the langurs of Abu, Rajasthan. Folia Primatologica 22: 19 -58

Joslin, P. (1973). The Asiatic lion: a study of ecology and behaviour., Ph.D. Thesis, University of Edinburgh, 248pp.

Khan, J.A., R. Chellam, W.A. Rodgers \& A.J.T. Johnsingh (1996) Ungulate density and biomass in the tropical dry deciduous forests of Gir, Gujarat, India. Journal of Tropical Ecology 12: 149-162

Khan, J.A., R. Chellam \& A.J.T. Johnsingh (1995). Group size and agesex composition of three major ungulate species in Gir lion sanctuary, Gujarat, India. Journal of Bombay Natural History Society. 92: 295-302.

Kinnear, N.B. (1920). The past and present distribution of the lion in South Eastern Asia. Journal of Bombay Natural History Society 27: 3339

Kleiman, D.G. \& J. R. Malcolm (1981). The evolution of male parental investment in mammals, pp.347-387. In: Gubernick, D.J. \& P.H. Klopfer (eds.). Parental Care in Mammals. Plenum Publishing, New York.

Loveridge, A.J. (2005). Impact of sport hunting on the lion population of Hwange NP, Zimbabwe in Lion Conservation Research: workshops 3\&4: Loveridge, A.J., Lynam, T. and Macdonald, D.W. 2005 Lion Conservation Research - Workshop 3 \& 4: from conflict to socioecolgy

Macdonald, D.W. (1983). The ecology of carnivore social behaviour. Nature 301: 379-384.

Meena, V. (2008). Reproductive strategy and behaviour of male Asiatic Lions. Ph.D. Thesis (Submitted), Forest Research Institute University, Dehradun, Uttarakhand, India.

Meena, V., Y.V. Jhala, R. Chellam \& B.J. Pathak (2007). Demography of the Asiatic Lions in the Gir Forest, India. Abstract: Felid Biology and Conservation Conference, September (18-20) 2007. Oxford, 33pp.

Nowell, K. \& P. Jackson (1996). Wild Cats. Status Survey and Conservation Action Plan. IUCN/SSC Cat Specialist Group. IUCN, Gland, Switzerland. 382pp.

O’Brien, S., J. Martenson, C. Packer, L. Herbst, V. de Voss, P. Jocelyn, J. Ott-Jocelyn, D. Wildt \& M. Bush (1987). Biochemical genetic variation in geographic isolates of African and Asiatic Lions. National Geographic Research 3: 114-124.

Ogutu, J.O. \& H.T. Dublin (2002). Demography of lions in relation to prey and habitat in the Maasai Mara National Reserve, Kenya. African Journal of Ecology 40: 120-129

Oxford H.J.L., M.R. Perrin \& H.H. Berry (1988). Contraception, reproduction and demography of free ranging Ethosha Lions (Panthera leo). Journal of Zooogy, London 216(4): 717-733.

Packer, C. \& A.E. Pusey (1982). Cooperation and competition within coalitions of male lions: kin selection or game theory? Nature 296 (5859): 740-742.

Packer, C. \& A.E. Pusey (1983). Adaptations to female lions to infanticide by incoming males. American Naturalist. 121(5) 716-728.

Packer, C. \& A.E. Pusey (1987). Intrasexual cooperation and the sex ratio in African lions. American Naturalist 130(4): 636-642.

Packer, C. \& T.M. Caro, (1997). Foraging costs in social carnivores. Animal Behaviour 54: 1317-1318

Packer, C., L. Herbst, A.E. Pusey, J.D. Bygott, J.P. Hanby, S.J. Cairns \& Borgerhoff-Mulder (1988). Reproductive success of lions, pp.363383. In: Clutton-Brock, T.H. (ed.). Reproductive Success. Univ. Chicago Press, Chicago.

Packer, C., D.A. Gilbert, A.E. Pusey \& S.J.O’Brien (1991). A molecular genetic analysis of kinship and cooperation in African lions. Nature 
$351(6327): 562-565$

Pathak, B.J., B.P. Pati, R. Kumar, A. Kumar, P.P. Raval, V.S. Patel \& V.J. Rana (2002). Biodiversity Conservation Plan for Gir. Supplementary Management Plan, 407pp.

Purchase, G.K. (2004). Factors affecting the ratio of lion Panthera leo to spotted hyaenas Crocuta crocuta in protected areas of Africa: competition and/or available prey. PhD Thesis, University of Aberdeen, pp.169-184.

Schaller, G. (1972). The Serengeti Lion. University of Chicago, Chicago, 480 pp.

Scheel, D. \& C. Packer (1995). Variation in predation by lions: Tracking a movable feast, pp.299-314. In: Sinclair, A.R.E. \& P. Arcese (eds.). Serengeti II: Dynamics, Management and Conservation of an Ecosystem. Chicago: University of Chicago press.

Singh, H.S. (1997). Population dynamics, group structure and natural dispersal of the Asiatic lion Panthera leo persica. Journal of Bombay Naural History Society 94: 65-70.

Singh, H.S. \& R.D. Kamboj (1996). Biodiversity Conservation Plan for Gir: A Management Plan for Gir Sanctuary. Vol 1. Gujarat Forest Department, $242 \mathrm{pp}$

Spong, G. (2002). Space use in lions Panthera leo in the Selous Game Reserve: social and ecological factors. Behavioural Ecology and Sociobiology. 52: 303-307.
Stander, P.E. (1992). Foraging dynamics of lions in a semi-arid environment. Canadian Journal of Zoology 70: 8-24.

Stander, P.E., P.J. Haden, Kaqece \& Ghau (1997). The Ecology of asociality in Namibian Leopards. Journal of Zoology, London 242: 343-364.

Sunquist, M.E. (1981). The Social Organization of Tigers (Panthera tigris) in Royal Chitawan National Park, Nepal. Smithsonian Contributions to Zoology 336. Smithsonian Institution, Washington D.C.: P. 92

Turner, A. \& M. Antón (1997). The big cats and their fossil relatives Columbia University Press; New York, NY, 234pp.

Yamaguchi, N., A. Cooper, L. Werdelin \& D.W. Macdonald (2004). Evolution of the mane and group-living in the lion Panthera leo: a review. Journal of Zoology, London 263: 329-342.

Yamazaki, K. (1996). Social variation of lions in a male-depopulated area in Zambia. Journal of Wildlife Management 60: 490-497. 